\title{
Nanostructured Microemulsion Phase Behavior Using AOT or Extended Surfactant Combined with a Cationic Hydrotrope
}

\author{
Khalid Kanan, Hala Yousef, Ibrahim Kayali \\ Department of Chemistry \& Chemical Technology, College of Science \& Technology, Al-Quds University, Jerusalem, Palestine. \\ Email: kkanan@admin.alquds.edu
}

Received October $14^{\text {th }}, 2011$; revised November $20^{\text {th }}, 2011$; accepted November $29^{\text {th }}, 2011$

\begin{abstract}
The phase behavior for systems containing sodium bis(2-ethylhexyl sulfosuccinate) (AOT), with the cationic hydrotrope tetraethyl ammonium chloride (TEAC), in the presence of water and heptane were studied. Formulations of microemulsion for such systems and for systems containing the so called "extended surfactant" were carried out at different salt concentrations. Anisotropy was detected using cross polarizers and polarized microscopy. Ultralow interfacial tension for microemulsion was measured, first theoretically using the Chun-Huh equation, and then experimentally using spinning drop experiments. The presence of short chain hydrotropes (TEAC) was found to destabilize the liquid crystalline region, observed in the AOT/water/heptane phase diagram. Ultralow interfacial tensions were observed for microemulsions formulated with surfactant concentrations as low as $0.5 \%$, for both AOT and "extended surfactant" systems. The effect of temperature on the phase behavior of a microemulsion formed with AOT system was studied and found to behave in an opposite manner compared to the nonionic surfactant.
\end{abstract}

Keywords: Middle Phase Microemulsion; Cationic Hydrotrope; Ultra Low Interfacial Tension

\section{Introduction}

The outstanding properties of microemulsions such as thermodynamic stability, high solubilizing capacity and ultralow interfacial tension (IFT) make them desirable for applications in many fields including enhanced oil recovery (EOR), surfactant enhanced aquifer remediation (SEAR), detergency, pharmaceuticals and cosmetic preparations [1-3].

The high amount of surfactants required to formulate a microemulsion $(20 \mathrm{wt} \%$ or more) constitute a major problem for its usage. Also, most of the work on microemulsions formed with anionic surfactants utilized short to medium chain alcohols as co-surfactants and cosolvents in order to promote the formation of microemulsions, rather than the liquid crystalline phase, which is favored by more rigid surfactant films. However, inclusion of alcohol in the formula may cause undesirable effects in many applications [4].

The anionic surfactant Aerosol-OT, also known as AOT, with its double tail can form microemulsions with no alcohols required. The phase diagram of brine/AOT/ decane system that was determined earlier showed that the reverse micellar solution L2, can dissolve large amounts of water thus forming bicontinuous or discrete droplet microemulsion [5]. AOT was also found to change from hydrophobic to hydrophilic species with increasing temperature.

Mixing anionic and cationic surfactants was earlier found to exhibit strong synergistic effects [6]. Alcoholfree middle phase microemulsion was prepared without the formation of a liquid crystalline phase [7], and the IFT dropped below $0.1 \mathrm{mN} / \mathrm{m}$ for certain systems using $0.1 \mathrm{M}$ surfactant concentration. In another investigation, using the "so called" extended surfactant systems, an ultra low IFT value was obtained using $0.1 \mathrm{M}$ surfactant concentration, meanwhile for the conventional surfactant AOT, the IFT values remained above $1 \mathrm{mN} / \mathrm{m}$ with various electrolyte concentrations [8]. In a more recent work, AOT was found to form middle phase microemulsion with different hydrocarbons only when a cationic hydrotrope (tetra ethyl ammonium chloride, TEAC) was combined with AOT [9]. Ultra low IFT values were predicted for such systems using the Chun Huh equation [10].

The present work reports an investigation of the ternary phase behavior, middle phase microemulsion, particle size and IFT values for AOT combined with cationic hydrotropes.A comparison of this system with the one using the extended surfactant, sodium alkyl poly propyl- 
ene oxide sulfate is also indicated.

\section{Experimental}

\subsection{Materials}

AOT surfactant (sodium bis(2-ethylhexyl) sulfosuccinate), minimum $99 \%$; tetra ethylammonium chloride $98 \%$, heptane, 99\% were all obtained from Sigma.

The extended surfactant, sodium alkyl polypropylene oxide sulfate, $\mathrm{C}_{12-13} \mathrm{H}_{25-27}(\mathrm{PO})_{4} \mathrm{SO}_{4} \mathrm{Na}\left(\mathrm{L}_{123}-4 \mathrm{~S}\right)$ comprising a branched hydrocarbon chain, which was $32.5 \mathrm{wt} \%$ active with $0.1 \mathrm{wt} \% \mathrm{Na}_{2} \mathrm{SO}_{4}, 2.5 \mathrm{wt} \%$ free oil and $64.9 \mathrm{wt} \%$ water, was donated by Sasol North America lnc (West lake, Louisiana). Polypropylene oxide quaternary ammonium chloride, Variquat cc-9 NS, purity $>90 \%$, was a gift from Evonik-Degussa, Germany. The propylene oxide chain, (mean chain-length unspecified by the manufacturer) was linked to the nitrogen atom of the quaternary ammonium group. Sodium chloride, $99.5 \%$, was purchased from Merck.

\subsection{Methods}

To determine the location and boundaries of the different phases of the first ternary phase diagram, samples were prepared by adding TEAC to preweighed mixtures of AOT and water in glass test tubes, which were then sealed by flame, homogenized and left to equilibrate at $25^{\circ} \mathrm{C}$ for one week. For the second and third ternary phase diagram, heptane was added to preweighed mixtures of AOT or AOT/TEAC and water, following the same procedure. The samples were checked for phase separation and birefringence. Cross polarizers were used to distinguish between anisotropic lamellar and hexagonal liquid crystal and isotropic (nonbirefringent) micellar or cubic liquid crystal. One-phase samples were clear and homogeneous, while two or three phase samples were either opaque or (macroscopically) phase separated. Samples inside and outside the demixing line were checked twice to ensure reproducibility of the results.

In formulating middle phase microemulsions, salinity scans were prepared by weighing appropriate amounts of surfactant (AOT or $\mathrm{L}_{123}-4 \mathrm{~S}$ ), TEAC or variquat cc-9, sodium chloride and water in $10 \mathrm{ml}$ glass test tubes, then shaking with a vortex for $1-2$ minutes. The appearance of the solution was checked visually for transparency and between cross polarizers for birefringence. After that, heptane was added at brine-oil weight ratio $($ WOR $=1$ ) and the tubes were mixed gently on a mixer for 12 hours. The tubes were then set in an upright position and allowed to settle.

The ultra low IFT was measured using a spinning-drop tensiometer (SITE, Kruss) owned by the institute of physical Chemistry, University of Koln, Koln, Germany.
IFT values as low as $10^{-5} \mathrm{mN} / \mathrm{m}$ could be measured. The IFT was calculated using Vonnegut equation that consider the injected oil drop to have the form of a cylinder with radius $r$ and length $l$

$$
\sigma=\frac{1}{4} \Delta \rho \omega^{2} r^{3}, \text { for } 1 \gg r
$$

where $\Delta \rho$ is the density difference of the two phases and $\omega$ is the angular velocity.

Particle size measurements were made on a zeta sizer Nano zs instrument at $25^{\circ} \mathrm{C}$.

\section{Results and Discussion}

\subsection{Ternary Phase Diagram of AOT/TEAC/Water System}

Binary phase diagram of AOT/water that was studied by Petrov [11], showed the formation of a large area of lamellar liquid crystal, with an AOT (very hydrophobic surfactant) in a water maximum solubility of $1.3 \mathrm{wt} \%$ at $25^{\circ} \mathrm{C}$. Ternary phase behavior was determined at $25^{\circ} \mathrm{C}$ in our lab by using the cationic hydrotrope, TEAC, as a third component with the AOT/water system, where a single clear isotropic phase was obtained as AOT was present at $4.8 \mathrm{wt} \%$, then the mixture turned rapidly to a single turbid phase at $9 \mathrm{wt} \%$ AOT, and appeared to be very thick at $13 \mathrm{wt} \%$ AOT . The addition of TEAC increases the solubility of AOT and causes the formation of the normal micelle L1 phase (Figure 1).

\subsection{Ternary Phase Diagram of AOT/Water/Heptane System}

A ternary phase diagram of AOT/water/heptane system has been constructed previously [12]. In our lab the resulting phase diagram (Figure 2) resembles the previous one in having a large area of inverse micelle L2 phase

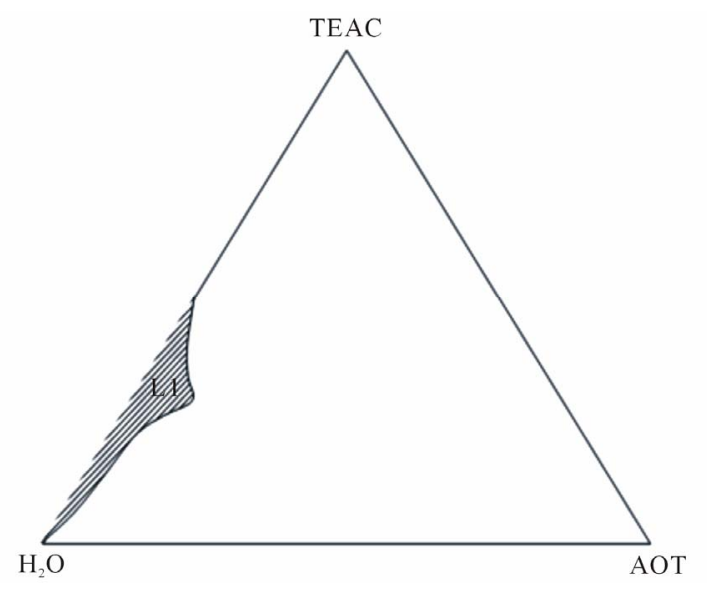

Figure 1. The isothermal phase diagram of three component system AOT/TEAC/water at $25^{\circ} \mathrm{C}$. $\mathrm{L1}$ represents the normal micelle area. 


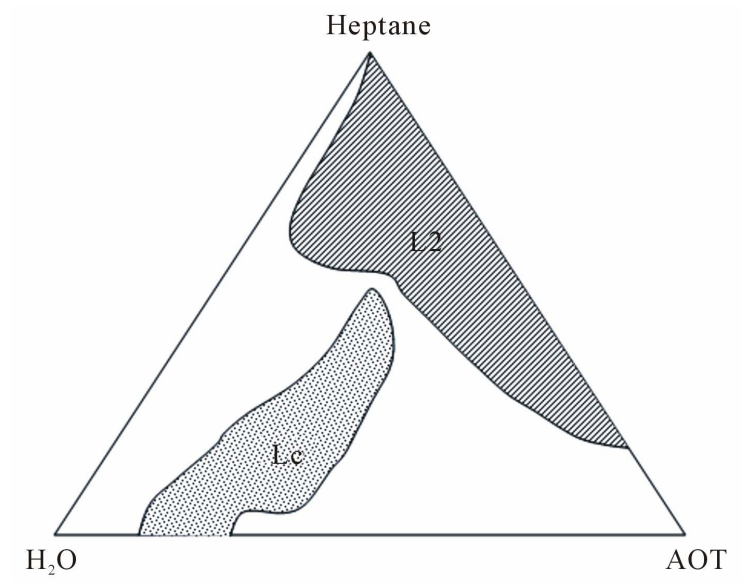

Figure 2. Ternary phase diagram of a system AOT/Water/ Heptane at $25^{\circ} \mathrm{C}$. $\mathrm{L} 2$ and Lc represent the reversed micelle and the liquid crystal respectively.

and in forming lamellar liquid crystal LC, but no L1 isotropic region appeared in our system. At the point of $25 \%$ surfactant, $25 \%$ water and $50 \%$ heptane, addition of surfactant changes the liquid crystal to inverse micelle structure. Large area of liquid crystal has been detected as expected.

\subsection{Ternary Phase Diagram of (AOT/TEAC 1:1 Molar Ratio)/Water/Heptane System}

The observed ternary phase diagram at $25^{\circ} \mathrm{C}$ is shown in Figure 3, the composition in L1 and L2 regions immediately shifts to transparent solution upon mixing.

Interesting phases were determined in comparison with Figure 2. The addition of hydrophobic TEAC cosurfactant in equimolar ratio changes the properties of AOT. TEAC increases the flexibility of AOT surfactant rigid film by increasing solubilization and penetration of oil. So decreasing the rigidity of surfactant film of AOT reduces the formation of LC. In our system first, the liquid crystal region diminished completely and was replaced by small area of normal micelle L1 region and second, the inverse micelle $\mathrm{L} 2$ region was abated towards the heptane corner by the addition of TEAC hydrotrope.

AOT molecule has double branched and long tail chain, and TEAC is a small hydrophobic molecule with small hydrocarbon side. According to hydrotrope properties it will be located at water oil interface together with the main surfactant AOT (Figure 4), this decreases the electrostatic attraction of the head groups of AOT, consequently the van der Waals attraction of tail chains of AOT decreases also because the tails become apart from each other, and thus synergistic effect is obtained, which enables additional solubilization of oil, and enhances the formation of middle phase microemulsion (Figure 5).

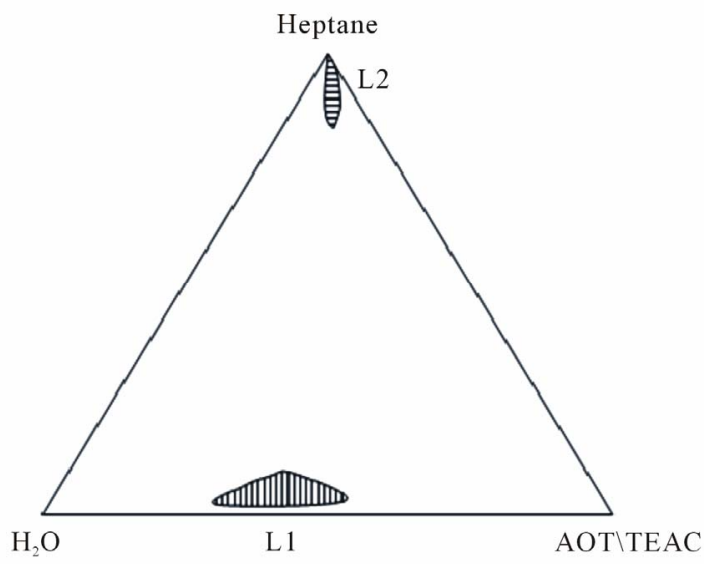

Figure 3. Ternary phase diagram of $\mathrm{H}_{2} \mathrm{O}$ /heptane/ (AOT: TEAC 1:1 molar ratio), $\mathrm{L} 1$ and $\mathrm{L} 2$ represent micelle and inverse micelle respectively.

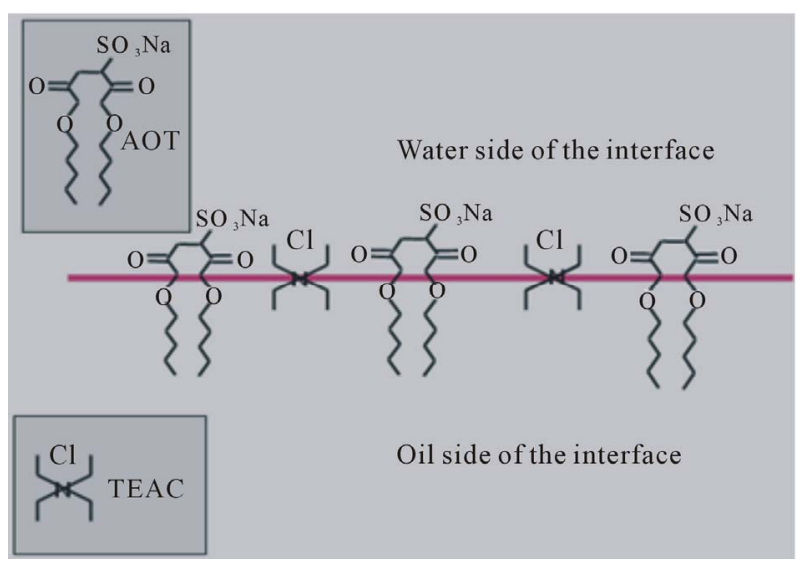

Figure 4. TEAC located at the water/oil interface as well as AOT.

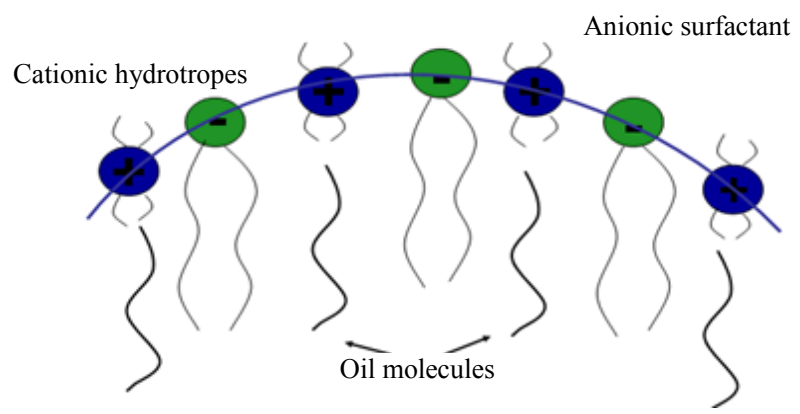

Figure 5. Anionic/cationic model which enables solubilization of additional oil, and formation of middle phase microemulsion.

\subsection{Fish Phase Diagram of AOT/TEAC (1:1) Molar Ratio WOR = 1 by Salinity Scan and Interfacial Tension Measurement}

The effect of salt concentration and temperature on phase behavior of AOT with cationic hydrotrope TEAC in 
equimolar ratio, and WOR $=1$ using heptane as a model oil was studied in order to understand the whole solution behavior of surfactant mixture. It was compared with previous work by Kayali [9], and were found to be exactly identical. In a previous work, Shinoda and Kunieda [5] studied the effect of salt concentration on the phase behavior of brine/AOT/ decane system by constructing fish phase diagram, they found that middle phase microemulsion occurs at $2 \mathrm{wt} \%$ AOT with brine $0.7 \% \mathrm{NaCl}$ at $42^{\circ} \mathrm{C}$.

Our systems of salinity scan containing $0.5 \%$ AOT: TEAC 1:1 molar ratio show matches with conventional Winsor I, III, II transitions in Figures 6-8 at $15^{\circ} \mathrm{C}, 25^{\circ} \mathrm{C}$, $45^{\circ} \mathrm{C}$, where the optimal salinities were $0.22,0.27$, $0.29 \mathrm{wt} \% \mathrm{NaCl}$ respectively. While without TEAC no Winsor premises occurs at the same salt concetraion [9].

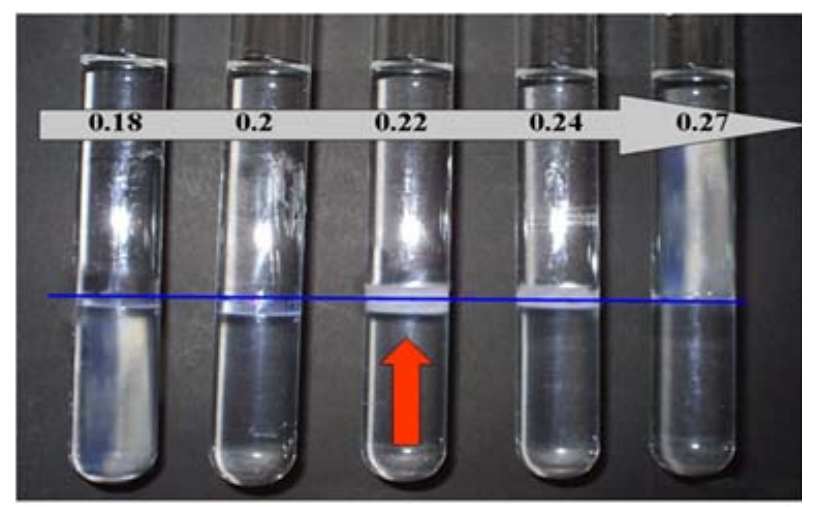

salinity scan for $0.5 \%$ AOT, TEAC ( $1: 1$ molar ratio) with heptane, $\mathrm{WOR}=1$ at $45^{\circ} \mathrm{C}$

Figure 6. Salinity scan for $0.5 \%$ AOT/TEAC (1:1) molar ratio with heptane $\mathrm{WOR}=1$ at $15^{\circ} \mathrm{C}$ The arrow indicates the optimal salinity at $0.22 \mathrm{wt} \% \mathrm{NaCl}$. The horizontal line represents the amount of original oil and water.

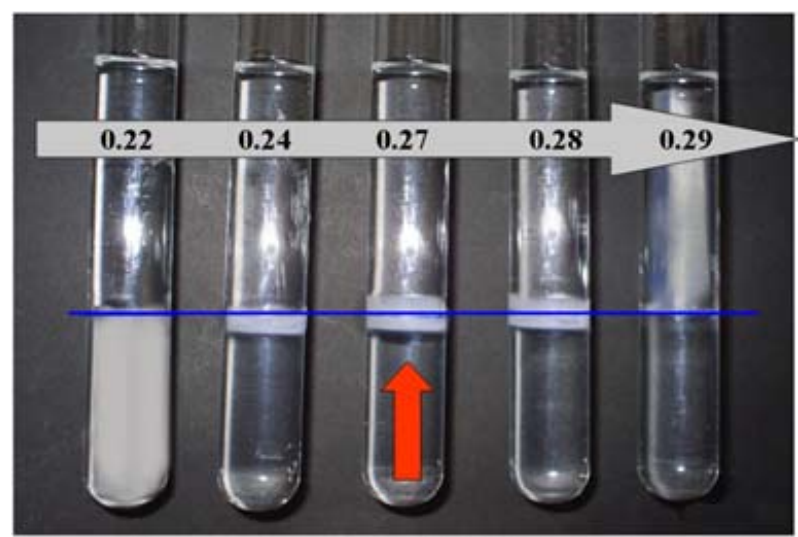

Salinity scan for $0.5 \%$ AOT, TEAC (1:1 molar ratio) with heptane, WOR $=1$ at $45^{\circ} \mathrm{C}$

Figure 7. Salinity scan for $0.5 \%$ AOT/TEAC (1:1) molar ratio with heptane $\mathrm{WOR}=1$ at $25^{\circ} \mathrm{C}$, the arrow indicates the optimal salinity at $0.27 \mathrm{wt} \% \mathrm{NaCl}$. The horizontal line represents the amount of original oil and water.
Also the effects of surfactant mixture concentration in different brine aqueous solutions were studied by constructing fish phase diagram Figure 9,where the middle phase microemulsion (Winsor III) is formed with wide range $(0.4 \%-9 \%)$ of surfactant mixture concentration. While in Shinoda study [5], the maximum concentration of surfactant was $6.5 \%$ AOT solution alone, so the addition of TEAC to AOT solution changes the behavior of solution completely.

AOT is an ionic surfactant; it is highly affected by salt concentration, at low salt concentration below $0.22 \%$ $\mathrm{NaCl}$ the AOT brine solution mixture is soluble in water, and it form micelles which coexist with excess oil, we assume this phase Winsor I Figure 9, so AOT is more hydrophilic at this point, and upon addition of TEAC cationic hydrotope (1:1) molar ratio to AOT solution the hydrophilic lipophilic value (HLB) will increase, and thus the mixture need lower salt concentration in order to form middle phase microemulsion.

On the contrary at high salt concentration, above $0.3 \%$

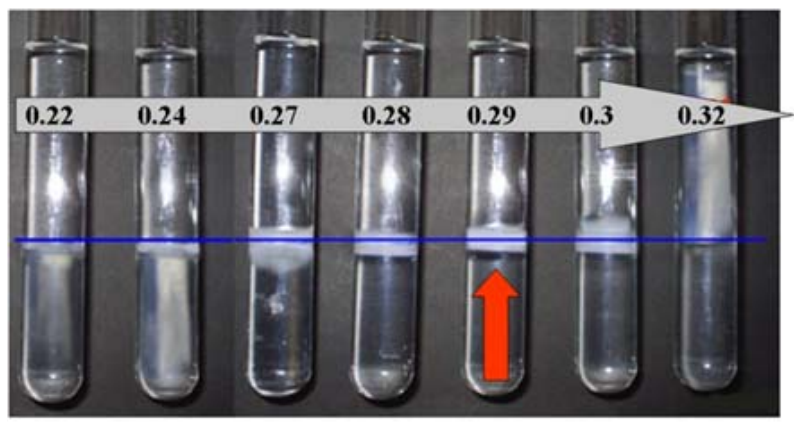

Salinity scan for $0.5 \%$ AOT, TEAC (1:1 molar ratio) with heptane, WOR $=1$ at $45^{\circ} \mathrm{C}$

Figure 8. Salinity scan for $0.5 \%$ AOT/TEAC (1:1) molar ratio with heptane $\mathrm{WOR}=1$ at $45^{\circ} \mathrm{C}$, the arrow indicates the optimal salinity at $0.29 \mathrm{wt} \% \mathrm{NaCl}$. The horizontal line represents the amount of original oil and water.

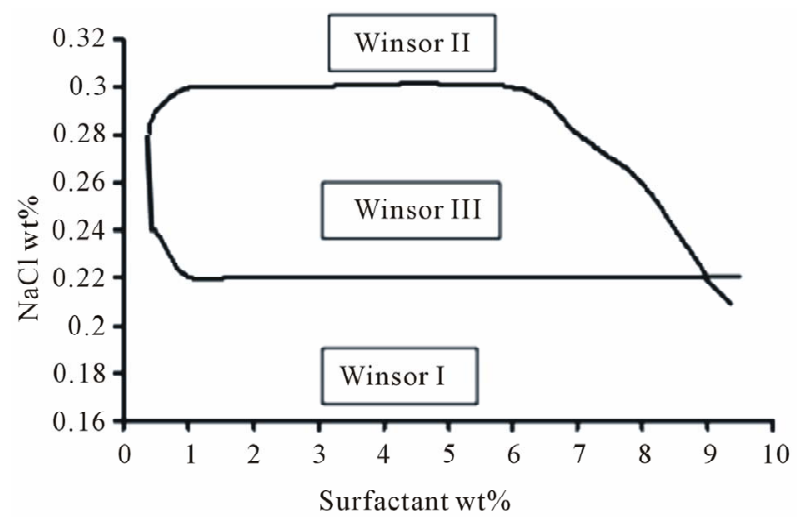

Figure 9. Phase diagram of AOT/TEAC (1:1) molar ratio (surfactant \%), with brine/heptane (1:1) weight ratio, as a function of salt concentration $(\mathrm{NaCl} \%)$ at $25^{\circ} \mathrm{C}$. 
$\mathrm{NaCl}$ non-aqueous reversed miceller solution coexist with an excess water phase (Winsor II), because of increasing lipophilic properties of AOT, so at this point the (HLB) is decreased, and the addition of equimolar ratio of TEAC, the lipophilcity is also reduced largely, but still behaves as Winsor II.

In between the above two phases $(0.22 \%-0.3 \% \mathrm{NaCl})$, an intermediate phase consisting of three phase region of water, surfactant and oil (winsor III) is present at hydrophilic lipophilic balanced point (HLB). Below this phase the natural curvature of the surfactant film $(\mathrm{Ho}<0)$ (winsor I), and above it (Ho >0) (winsor II). This phase is claimed to be termed surfactant phase or middle phase because it contains the total amount of surfactant in the mixture, with minimum amount of solubilized oil and solubilised water. The surfactant range in the middle phase is from $5.2-6 \mathrm{wt} \%$ according to salt concentration Table 1.

The unique balanced hydrophile-lipophile properties of AOT result in solution behavior similar to non-ionic surfactant at constant brine concentration, that is behave in reverse way. AOT is dissolved in the oil phase at low temperature and forms reversed micellar solution (w/o), with excess water. Contrariwise AOT is dissolved in the water phase at high temperature forming $(\mathrm{o} / \mathrm{w})$ microemulsion in equilibrium with excess oil.

Figure 10 shows phase behavior of AOT/TEAC (1:1 molar ratio) with constant salt concentration $(0.24 \%$ $\mathrm{NaCl}$ ) and $\mathrm{WOR}=1$, at different temperatures. At $15^{\circ} \mathrm{C}$ the system was hydrophobic, the surfactant mixture dissolved in oil phase in equilibrium with excess water. The hydrophilicity increased by increasing temperature, until reaching $45^{\circ} \mathrm{C}$ the surfactant mixture became more hydrophilic forming $(\mathrm{o} / \mathrm{w})$ microemulsion in equilibrium with excess oil.

Previous study of Shinoda [5], showed that AOT/brine/ oil system had hydrophobic properties below $45^{\circ} \mathrm{C}$, while had hydrophilic properties above $45^{\circ} \mathrm{C}$. In our model by the addition of TEAC (1:1) molar ratio, the system became more hydrophilic by increasing temperature above $25^{\circ} \mathrm{C}$, and below it the surfactant became more hydrophobic.

Table 1. Solubilization ratio and IFT for a system AOT/ TEAC (1:1) molar ratio WOR $=1$ at $25^{\circ} \mathrm{C}$ using Chun-Huh equation, and wt $\%$ of surfactant in the middle phase assuming all surfactant in the middle phase.

\begin{tabular}{cccccc}
\hline $\begin{array}{c}\text { Salinity } \\
\mathrm{NaCl} \mathrm{wt} \%\end{array}$ & Solubilization & $\begin{array}{c}\text { IFT using } \\
\text { Chun-Huh equation } \\
c=0.3 \mathrm{mN} / \mathrm{m}\end{array}$ & $\begin{array}{c}\text { wt\% of } \\
\text { surfactant } \\
\text { in middle } \\
\text { phase }\end{array}$ \\
\cline { 2 - 5 } 0.24 & 3.3 & 13.3 & 0.0275 & 0.0017 & 6 \\
0.27 & 12.3 & 6.6 & 0.0019 & 0.0069 & 5.3 \\
0.28 & 15.7 & 3.3 & 0.0012 & 0.0275 & 5.2 \\
\hline
\end{tabular}

The solubilization ratio and interfacial tension at the middle phase can be predicted using the Chun-Huh equation at middle phase, Table 1, as the following:

$$
\sigma_{m o}=c /\left(V_{o} / V_{s}\right)^{2}, \sigma_{m w}=c /\left(V_{w} / V_{s}\right)^{2},
$$

where $\sigma_{m o}$ is the IFT between the oil phase and surfactant phase, $\left(V_{o} / V_{s}\right)$ is the ratio of solubilized oil volume to the total surfactant volume, $\sigma_{m w}$ the IFT between the water phase and surfactant phase, $\left(V_{w} / V_{s}\right)$ is the ratio of solubilized water volume to the total surfactant volume, and $c$ is a constant equal $0.3 \mathrm{mN} / \mathrm{m}$, which is found to be consistent with this type of system [13].

The above results are illustrated in Figure 11, it shows that IFT between heptane and middle phase $\left(\sigma_{m o}\right)$ falls down with increasing salinity from 0.0275 to 0.0012 $\mathrm{mN} / \mathrm{m}$. While IFT between water and middle phase $\left(\sigma_{m w}\right)$ rise up by increasing salinity from 0.0017 to 0.0275 $\mathrm{mN} / \mathrm{m}$. the figure shows that the IFT at 0.265 is equal at water and oil side which mean this point is the middle phase.

These IFT results were confirmed using a spinning drop tensiometer; the results are consistent with the Chun-Huh result calculations, that both methods produce ultralow interfacial tension, which mean this system is

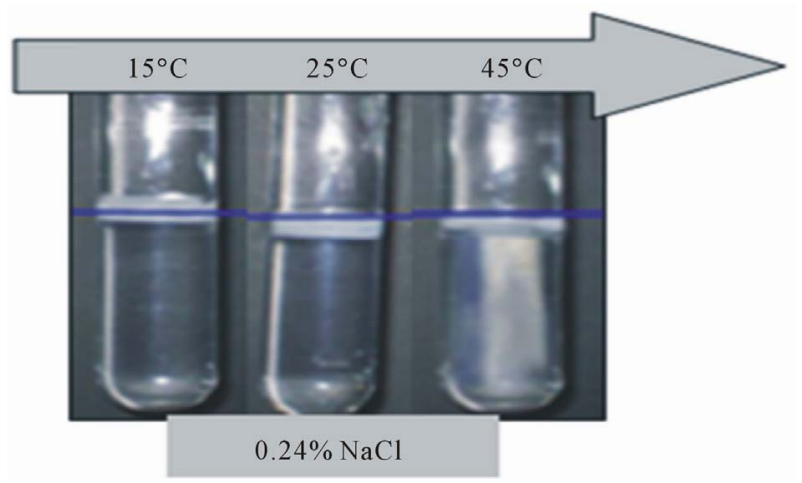

Figure 10. Phase behavior of AOT/TEAC (1:1) molar ratio, WOR $=1$, at constant salt concentration $(0.24 \% \mathrm{NaCl})$, at $15^{\circ} \mathrm{C}, 25^{\circ} \mathrm{C}, 45^{\circ} \mathrm{C}$.

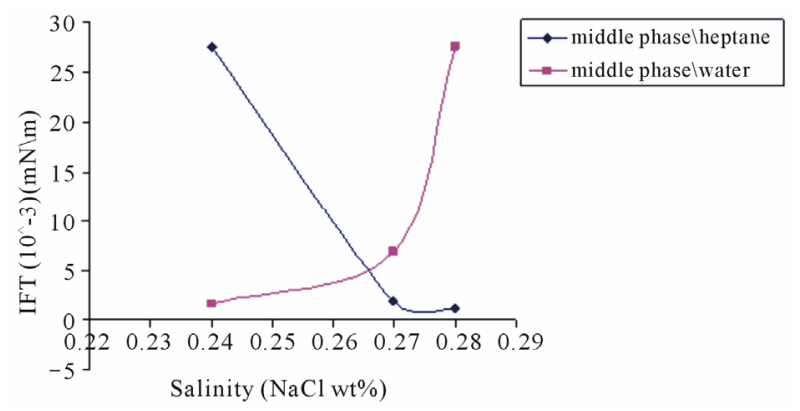

Figure 11. IFT versus $\mathrm{NaCl}$ wt $\%$ concentration as predicted by Chun-Huh equation, for a system $0.5 \%$ AOT: TEAC (1:1) molar ratio, $\mathrm{WOR}=1$. 
applicable in many industrial fields that need ultralow IFT for their formulations.

For measuring the IFT by spinning drop tensiometer, 5 $\mathrm{ml}$ of brine was injected into glass tube of spinning drop with one drop of middle phase at $0.24 \%, 0.27 \%, 0.28 \%$ $\mathrm{NaCl}$, and allow rotating horizontally until maximum elongation of middle phase drop, at this point the angular velocity measured was compensated in Vonnegut equation [14], and IFT $(\sigma)$ was obtained. The same procedure was done between middle phase and heptane. The results are illustrated in Table 2.

Spinning drop results are illustrated in Figure 12, the IFT between brine and middle phase fall down until reached optimum salinity $(0.28 \% \mathrm{NaCl})$ which equal $0.0002 \mathrm{mN} / \mathrm{m}$, after this point the IFT rise up again. Also the IFT between brine and heptane has ultralow value equal $0.0048 \mathrm{mN} / \mathrm{m}$.

\subsection{Phase Behavior of L123-4S/Variquat-cc9 (1:1) Molar Ratio WOR = 1 by Salinity Scan and Interfacial Tension Measurement}

Phase behavior of extended surfactant by salinity scan can produce ultralow IFT close to $0.001 \mathrm{mN} / \mathrm{m}$ at optimum salinity, while for conventional surfactant AOT the IFT remains above $1 \mathrm{mN} / \mathrm{m}$ [8], this means the side chain

Table 2. IFT using spinning drop tensiometer, between brine and heptane, and between brine and middle phase for a system 0.5\% AOT: TEAC (1:1) molar ratio, WOR = 1 .

\begin{tabular}{ccc}
\hline $\begin{array}{c}\text { Salinity } \\
\mathrm{NaCl} \%\end{array}$ & $\begin{array}{c}\text { IFT } \\
(\text { brine/heptane }) \\
(\mathrm{mN} / \mathrm{m})\end{array}$ & $\begin{array}{c}\text { IFT } \\
(\text { brine } / \text { middle phase }) \\
(\mathrm{mN} / \mathrm{m})\end{array}$ \\
\hline 0.24 & 0.0041 & 0.0009 \\
0.28 & 0.0049 & 0.0002 \\
0.30 & 0.012 & 0.006 \\
\hline
\end{tabular}

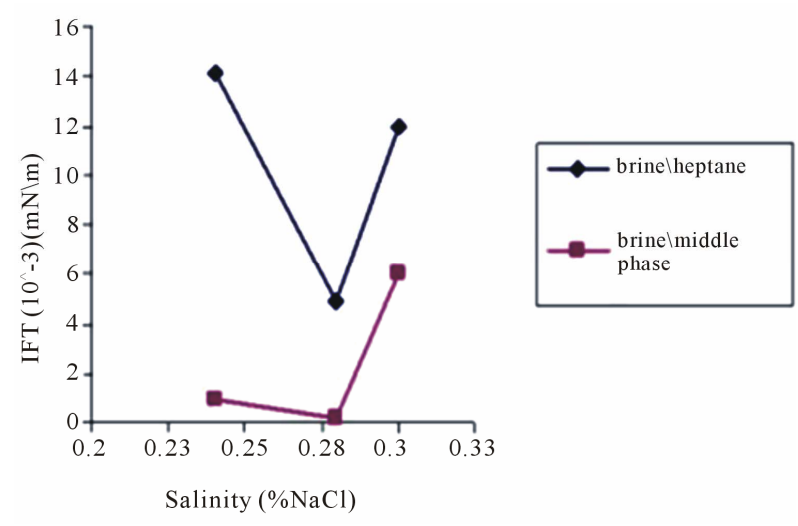

Figure 12. IFT between brine/Heptane, and brine/middle phase, for a system containing $0.5 \%$ AOT: TEAC (1:2) molar ratio, $\mathrm{WOR}=1$. of polyethylene-polypropylene oxide of extended surfactants give special properties of ultralow IFT and high solubilization capacity, and low CMC, such information is promising for detergency and EOR where concentrated amount of surfactant is needed.

While studying Phase behavior of extended surfactant L123-4S with cationic hydrotropes Variquat-cc9 (1:1) molar ratio at low concentration reached $0.5 \%$ with water: heptane $(1: 1)$ weight ratio, the system produced ultralow IFT close to $0.00075 \mathrm{mN} / \mathrm{m}$ at optimum salinity, which are compatible with Kayali et al. study [15]. The system meets winsor premises transition from winsor I to winsor III to winsor II Figure 13, it shows that it has optimal salinity at $3.25 \% \mathrm{NaCl}$ concentration.

On the other hand, by comparing this system with previous AOT/TEAC system, the conventional AOT/TEAC system behaves as extended surfactant and produces ultralow IFT close to $0.0002 \mathrm{mN} / \mathrm{m}$ at optimum salinity, but with lower salt concentration than extended surfactant does.

Solubilization parameter and the IFT by chun-huh equation were determined in Table 3, it is clear that the solubilization ratio rise up from $3.3(\mathrm{ml}$ of heptane/g of surfactant) at $3 \% \mathrm{NaCl}$ to 21.7 at $3.5 \% \mathrm{NaCl}$, which will reduce the IFT to its lower value $0.0006 \mathrm{mN} / \mathrm{m}$ between heptane and middle phase. Contrariwise between water and middle phase the solubilization ratio fall down from a value of 18.3 at $3 \% \mathrm{NaCl}$ to 5 at $3.5 \% \mathrm{NaCl}$, which raises the IFT from 0.0009 to $0.012 \mathrm{mN} / \mathrm{m}$ (Figure 14).

These observations were correlated to phase behavior of most anionic surfactants, which at low salt concentration; below $2.5 \% \mathrm{NaCl}$ the mixture were highly hydrophilic and the surfactant dissolved in water, forming micelles coexist with excess oil, we assume this phase winsor I, on the contrary at higher salt concentration; above $4 \%$ the mixture became more hydrophobic and the surfactant dissolved in heptane forming inverse micelle with

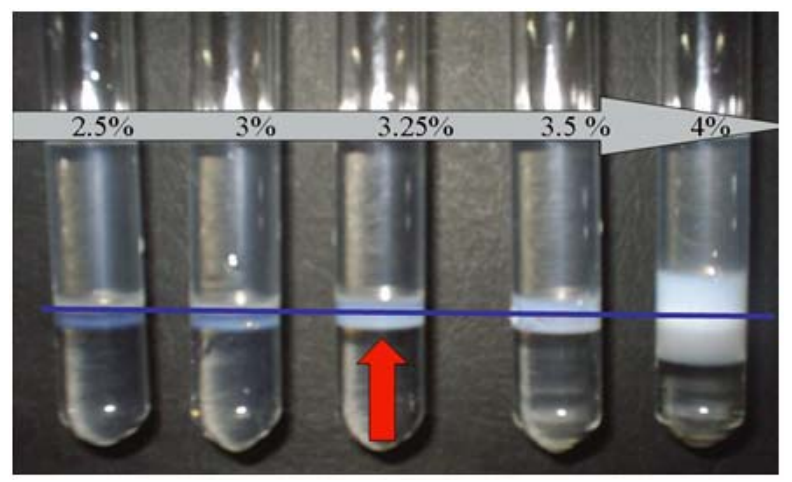

Figure 13. Salinity scan for $0.5 \%$ L123-4S/variquate-cc9 $(1: 1)$ molar ratio with heptane $\mathrm{WOR}=1$ at $25^{\circ} \mathrm{C}$, the arrow indicates the optimal salinity at $3.25 \mathrm{wt} \% \mathrm{NaCl}$. The horizontal line represents the amount of original oil and water. 
Table 3. Solubilization ratio and IFT for a system L1234S/variquate-cc9 (1:1) molar ratio WOR $=1$ at $25^{\circ} \mathrm{C}$ using Chun-Huh equation, and wt\% of surfactant in the middle phase assuming all surfactant in the middle phase.

\begin{tabular}{cccccc}
\hline \multirow{2}{*}{ Salinity NaCl\% } & \multicolumn{2}{c}{ Solubilization } & \multicolumn{2}{c}{$\begin{array}{c}\text { IFT using } \\
\text { chun-huh equation } \\
c=0.3 \mathrm{mN} / \mathrm{m}\end{array}$} & $\begin{array}{c}\text { wt\% of } \\
\text { surfactant in } \\
\text { middle phase }\end{array}$ \\
\cline { 2 - 5 } & $V_{o} / V_{s}$ & $V_{w} / V_{s}$ & $\sigma_{o}$ & $\sigma_{w}$ & \\
\hline 3 & 3.3 & 18.3 & 0.028 & 0.0009 & 4.6 \\
3.25 & 20 & 16.6 & 0.00075 & 0.001 & 3 \\
3.5 & 21.7 & 5 & 0.0006 & 0.012 & 3.7 \\
\hline
\end{tabular}

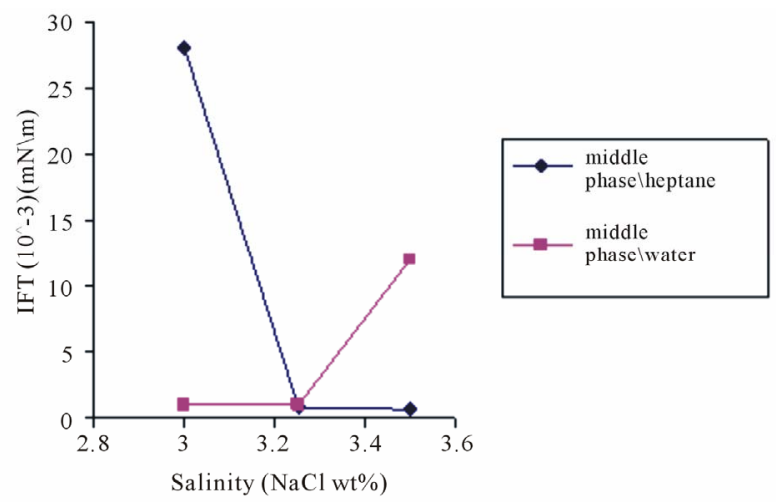

Figure 14. IFT versus $\mathrm{NaCl}$ wt \% concentration as predicted by Chun-Huh equation, for a system $0.5 \% \mathrm{L123}-4 \mathrm{~S} /$ variquate-cc9 (1:1) molar ratio, $\mathrm{WOR}=1$.

excess water, we assume this phase winsor II. In between these two phases $(2.5 \%-4 \% \mathrm{NaCl})$ precisely at $3.25 \%$ $\mathrm{NaCl}$, the surfactant mixture has balanced hydrophiliclipophilic properties (HLB) level, this phase is called winsor III or surfactant phase where the total amount of surfactant is present, and it ranges from $3 \%-4.6 \%$ (Table 3).

Predicted IFT by Chun- huh equation were illustrated in Figure 14, it had the lowest value at optimum 3.25\% $\mathrm{NaCl}$ which produced approximately $0.001 \mathrm{mN} / \mathrm{m}$.

Measuring the IFT by spinning drop tensiometer method, and compensating in Vonnegut equation, the results are illustrated in Table 4.

Figure 15 illustrates that IFT between brine and middle phase equal $0.0005 \mathrm{mN} / \mathrm{m}$, was reached at optimum salinity of $4 \% \mathrm{NaCl}$ after which the IFT rise up again. Also the IFT between brine and heptane has ultralow value of $0.0219 \mathrm{mN} / \mathrm{m}$ at $4 \% \mathrm{NaCl}$.

\section{Conclusions}

Cationic hydrotropes can be added to anionic surfactant for formulating alcohol free middle phase microemulsion with ultralow IFT, and high solubilization capacity, at minimum surfactant concentration.
Table 4. IFT using spinning drop tensiometer, between brine and heptane, and between brine and middle phase for a system 0.5\% L123-4S/variquate-cc9 (1:1) molar ratio, WOR $=1$.

\begin{tabular}{ccc}
\hline $\begin{array}{c}\text { Salinity } \\
\mathrm{NaCl} \%\end{array}$ & $\begin{array}{c}\text { IFT } \\
\text { (Brine/Heptane) } \\
\mathrm{mN} / \mathrm{m}\end{array}$ & $\begin{array}{c}\text { IFT } \\
\text { (Brine/middle phase) } \\
\mathrm{mN} / \mathrm{m}\end{array}$ \\
\hline 3.5 & 0.0248 & 0.0011 \\
4.0 & 0.0219 & 0.0005 \\
4.5 & 0.0503 & 0.0048 \\
\hline
\end{tabular}

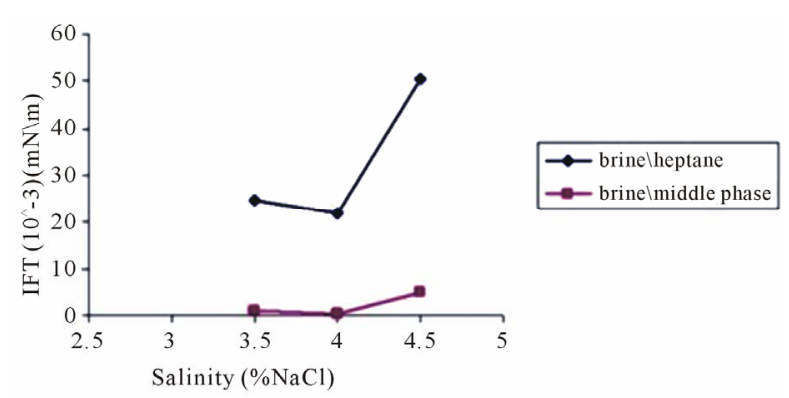

Figure 15. IFT between brine/Heptane, and brine/middle phase, for a system containing $0.5 \% \mathrm{L123}-4 \mathrm{~S} /$ variquate-cc9 (1:1) molar ratio, $\mathrm{WOR}=1$.

TEAC short chain cationic hydrotrope can be added to anionic AOT in (1:1) molar ratio at $0.5 \%$ surfactant concentration, and low salt concentration $(0.2 \%-0.3 \% \mathrm{NaCl})$, to produce ultralow IFT equal to $0.001 \mathrm{mN} / \mathrm{m}$ and even less. Such system can also produce middle phase microemulsion at different temperature which will be more hydrophilic by increasing temperature in constant brine solution.

In the same way addition of variquat-cc9 short chain cationic hydrotrope to $0.5 \%$ extended surfactant L123-4S in equimolar ratio with $\mathrm{WOR}=1$ and different salt concentration will produce middle phase microemulsion with ultralow IFT.

Finally we can conclude that addition of short chain cationic hydrotropes will change properties of AOT completely, which is considered as conventional surfactant, while addition of TEAC to AOT solution will raise its level to extended surfactant by producing ultralow IFT and high solubilization capacity.

\section{Future Work}

Both systems can be applied in EOR and SEAR efficiently at low surfactants concentration, without formation of liquid crystal and without addition of alcohol which will complicate the mentioned fields.

\section{Acknowledgements}

The authors would like to thank Professor Ulf Olsson at 
Physical Chemistry (1), Lund University Sweden, and Prof Rinhrd Strey and his group for the IFT measurements using their spinning drop tensiometer at the Physical Chemistry Institute, University of Koln, Koln, Germany. The authors express their gratitude to Sasol North America, Inc. and Sasol, Italy for kindly providing us with the extended surfactant samples and Evonic Goldschmjdt, Germany, for kindly providing us with the Variquat samples. This work was supported by the Swedish Research Council.

\section{REFERENCES}

[1] J. H. Harwell, D. A. Sabatini and R. C. Knox, "Surfactants for Ground Water Remediation," Colloids and Surfaces A: Physicochemical and Engineering Aspects, Vol. 151, No. 1, 1999, pp. 255-268.

[2] V. Dwarakanath and G. A. Pope, "Surfactant Phase Behavior with Field Degreasing Solvent," Environmental Science \& Technology, Vol. 34, No. 22, 2000. pp. 48424848. doi:10.1021/es0009121

[3] S. Heuschkel, A. Goebe and R. Neubert, "Microemulsions-Modern Colloidal Carrier for Dermal and Transdermal Drug Delivery," Journal of Pharmaceutical Sciences, Vol. 97, No. 2, 2008, pp. 603-631.

[4] B. J. Shiau, D. A. Sabatini, J. H. Harwell and D. Q. Vi, "Microemulsion of Mixed Chlorinated Solvents Using Food Grade (Edible) Surfactants," Environmental Science \& Technology, Vol. 30, No. 1, 1995, pp. 97-103. doi:10.1021/es9501169

[5] K. Shinoda and H. Kunieda, "The Effect of Salt Concentration, Temperature, and Additives on the Solvent Property of Aerosol OT Solution," Journal of Colloid and Interface Science, Vol. 118, No. 2, 1987, pp. 586-589.

[6] E. Marques, A. Khan, M. Miguel and B. Lindman, "Self-Assembly in Mixtures of a Cationic and an Anionic Surfactant: The Sodium Dodecyl Sulfate-Didodecyldimethylammonium Bromide-Water System," Journal of Physical Chemistry, Vol. 97, No. 18, 1993, pp. 4729-4736. doi: $10.1021 / \mathrm{j} 100120 \mathrm{a} 028$
[7] A. Unadhyaya, E. J. Acosta, J. F. Scamehron and D. A. Sabatini, "Microemulsion Phase Behavior of AnionicCationic Surfactant Mixtures: Effect of Tail Branching," Journal of Surfactants and Detergents, Vol. 9, No. 4, 2006, pp. 169-179.

[8] A. Witthyapanyanon, E. J. Acosta, J. H. Harwell and D. A. Sabatini, "Formulation of Ultralow Interfacial Tension Systems Using Extended Surfactants," Journal of Surfactants and Detergents, Vol. 9, No. 4, 2006, pp. 331-339. doi:10.1007/s11743-006-5011-2

[9] I. Kayali, K. Qamhieh and U. Olsson, "Microemulsion Phase Behavior of Aerosol-OT Combined with a Cationic Hydrotrope in the Dilute Region," Journal of Dispersion Science and Technology, Vol. 31, No. 2, 2010, pp. 183187. doi:10.1080/01932690903110293

[10] C. Huh, "Interfacial Tensions and Solubilizing Ability of a Microemulsion Phase That Coexists with Oil and Brine," Journal of Colloid and Interface Science, Vol. 71, No. 2, 1979, pp. 408-426.

[11] P. G. Petrov, S. V. Ahir and E. M. Terentjev, "Rheology at the Phase Transition Boundary: 1. Lamellar L-Alpha Phase of AOT Surfactant Solution," Langmuir, Vol. 18, No. 24, 2002, pp. 9133-9139.

[12] Y. Luan, G. Xu, G. Dai, Z. Sun and H. Liang, "The Interaction between Poly(Vinylpyrrolidone) and Reversed Micelles of Water/AOT/n-Heptane," Colloid and Polymer Science, Vol. 282, No. 2, 2003, pp. 110-118. doi:10.1007/s00396-003-0900-7

[13] S. Liu, D. L. Zhang, W. Yan, et al., "Favorable Attributes of Alkaline-Surfactant-Polymer Flooding," SPE Journal, Vol. 13, No. 1, 2008, pp. 5-16. doi:10.2118/99744-PA

[14] B. Vonnegut, "Rotating Bubble Method for the Determination of Surface and Interfacial Tensions," Review of Scientific Instruments, Vol. 13, No. 1, 1942, pp. 6-9. doi:10.1063/1.1769926

[15] I. Kayali, K. Qamhieh and U. Olsson, "Formulating Middle Phase Microemulsions Using Extended Anionic Surfactant Combined with Cationic Hydrotrope," Journal of Dispersion Science and Technology, Vol. 32, 2011, pp. 41-46. doi:10.1080/01932690903543303 